\title{
Intraosseous lipoma of the third lumbar spine: a case report
}

\author{
Chaipond Teekhasaenee ${ }^{1,2}$, Koji Kita $^{3}$, Kenji Takegami ${ }^{3}$, Eiji Kawakita ${ }^{3}$, Toshihiko Sakakibara ${ }^{1}$ and Yuichi Kasai ${ }^{*}$
}

\begin{abstract}
Introduction: Intraosseous lipoma is a benign bone tumor, and the tumor occurs more frequently in the lower extremities. We present a very rare case of intraosseous lipoma occurring in the lumbar vertebral arch and spinous process.

Case presentation: A 54-year-old Japanese man presented with a three-month history of lumbar pain. Magnetic resonance imaging of the L3 vertebral arch and spinous process revealed high intensity on T1- and T2-weighted imaging, and it was suppressed on fat-suppression imaging and no enhancement showed on gadolinium contrast-enhanced imaging. Computed tomography imaging revealed an osteolytic change accompanied by marginal osteosclerosis in his third lumbar vertebral arch and spinous process, as well as a thinned and bulging bone cortex. An analgesic had been administered prior to his visit, but low back pain had persisted, so we performed curettage and filled the defect with hydroxyapatite bone. His low back pain was improved immediately after surgery, and no recurrence of tumor has been observed on computed tomography imaging as of three years postoperatively.
\end{abstract}

Conclusions: Symptomatic intraosseous lipoma of spine is very rare, but the patient may be surgically well-treated by curettage and reconstruction of the benign tumor.

Keywords: Intraosseous lipoma, Lumbar spine, Benign spinal tumor, Surgery, Low back pain

\section{Introduction}

Intraosseous lipoma is a benign bone tumor, and the tumor occurs more frequently in the lower extremities. We present a very rare case of intraosseous lipoma occurring in the lumbar vertebral arch and spinous process, together with a discussion of the literature.

\section{Case presentation}

A 54-year-old Japanese man presented to our universityaffiliated hospital with a three-month history of lumbar pain. He was $167 \mathrm{~cm}$ in height and weighed $58 \mathrm{~kg}$. An analgesic had been administered prior to his visit, but low back pain had persisted. His physical examination showed pressure pain and tapping tenderness at the third lumbar vertebral level, but no sensory or motor disorders of his lower extremities. His blood biochemistry showed

\footnotetext{
* Correspondence: ykasai@clin.medic.mie-u.ac.jp

${ }^{1}$ Department of Spinal Surgery and Medical Engineering, Mie University Graduate School of Medicine, 2-174 Edobashi, Tsu city, Mie 514-8507, Japan Full list of author information is available at the end of the article
}

no abnormalities and his medical history was noncontributory.

A plain radiography revealed the formation of a vertebral spur or narrowing of the intervertebral disc between L3 and L4 as an age-related change, but no instability was evident between vertebrae and no obvious abnormalities were evident. Magnetic resonance imaging (MRI) of the L3 vertebral arch and spinous process revealed high intensity on T1- and T2-weighted imaging (Figure 1A,B,C), and it was suppressed on fat-suppression imaging (Figure 1D) and no enhancement showed on gadolinium (Gd) contrast-enhanced imaging (Figure 1E). Computed tomography (CT) imaging revealed an osteolytic change accompanied by marginal osteosclerosis in his third lumbar vertebral arch and spinous process, as well as a thinned and bulging bone cortex (Figure 2). Hounsfield units (HU) of CT for the area at which the osteolytic change was observed was $-87 \mathrm{HU}$, a value approximating that of fatty tissue, and areas of ossification or calcification were observed.

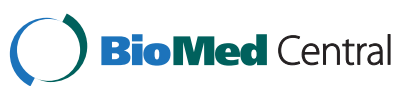




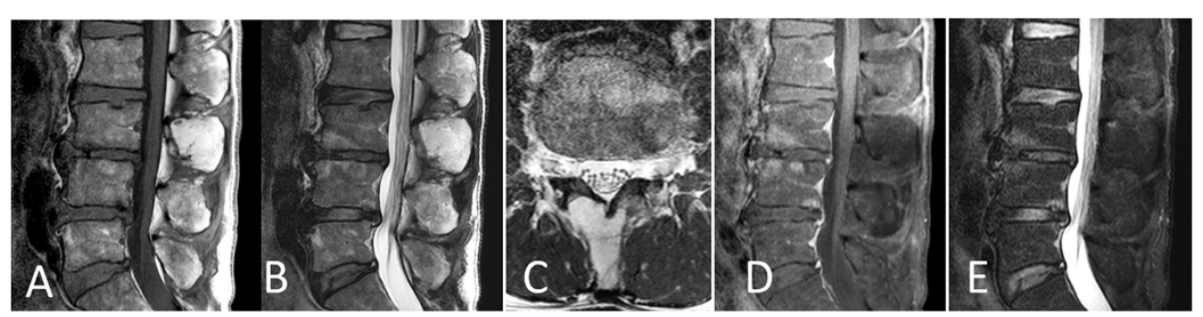

Figure 1 Magnetic resonance imaging at the L3 vertebral arch and spinous process. (A) Sagittal T1-weighted image; (B) Sagittal T2-weighted image; (C) Axial T2-weighted image; (D) Sagittal fat suppression image; (E) Sagittal T1-weighted gadolinium contrast (+) image.

Based on the above findings, although we suspected painful lipoma in the third lumbar vertebral arch and spinous process segment, we decided to perform a biopsy to confirm the diagnosis. Since a benign tumor was suspected, we planned to perform curettage of the tumor and to fill the defect with artificial bone.

The operation was performed under general anesthesia. The third lumbar vertebral arch was exposed, and when an area approximately $1 \mathrm{~cm} \times 1 \mathrm{~cm}$ in the external lamina of the right vertebral arch was opened, a yellow tumorous lesion with a color and elasticity macroscopically similar to those of ordinary fatty tissue was observed. The tumorous lesion was curetted away as much as possible, hydroxyapatite bone filler paste (BIOPEX'; HOYA Corporation,

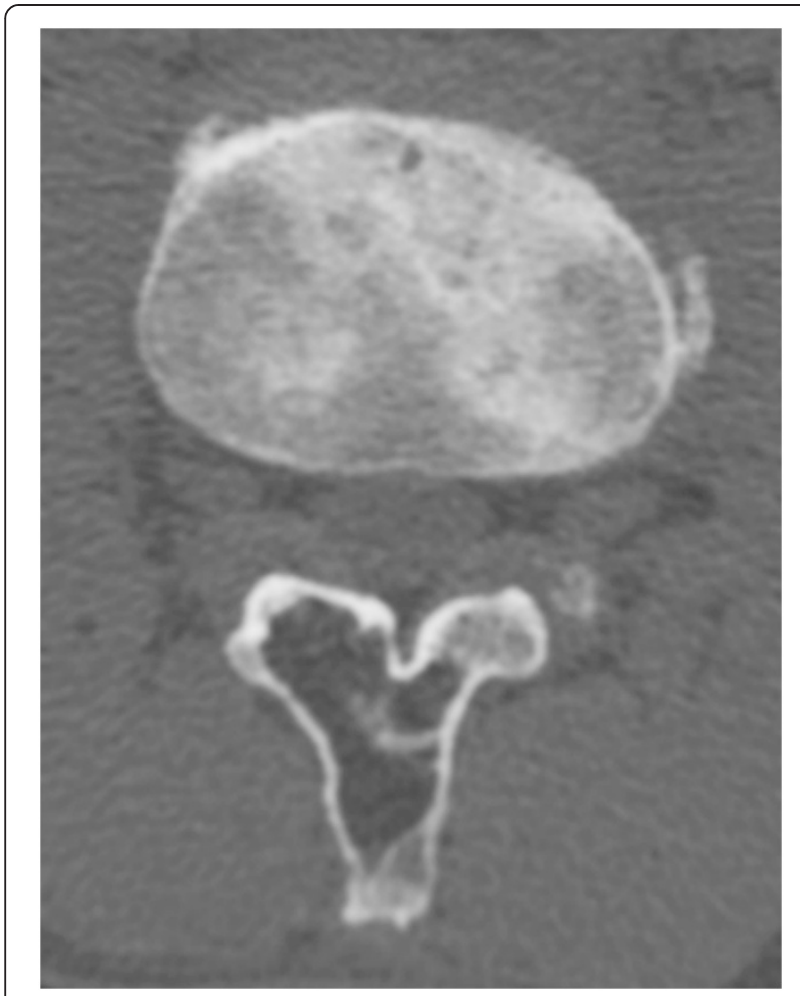

Figure 2 Computed tomography image revealing an osteolytic change accompanied by marginal osteosclerosis in his third lumbar vertebral arch and spinous process, as well as a thinned and bulging bone cortex.
Tokyo, Japan) was used to fill the defect and the external lamina of the vertebral arch was replaced. Intraoperative pathological findings included hyperplasia of adipose cells and blood vessels, a small amount of trabecular bone and adipose cells of different sizes. Intraosseous lipoma was therefore diagnosed (Figure 3).

His low back pain was improved immediately after surgery, and no recurrence of the tumor has been observed on CT imaging as of three years postoperatively (Figure 4).

\section{Discussion}

Despite the abundance of adipose connective tissue in bone marrow, intraosseous lipoma is extremely rare [1]; a search of PubMed using the keywords intraosseous lipoma' yielded 177 results. A review of the search results showed that intraosseous lipoma occurs more frequently in the lower extremities, particularly in the

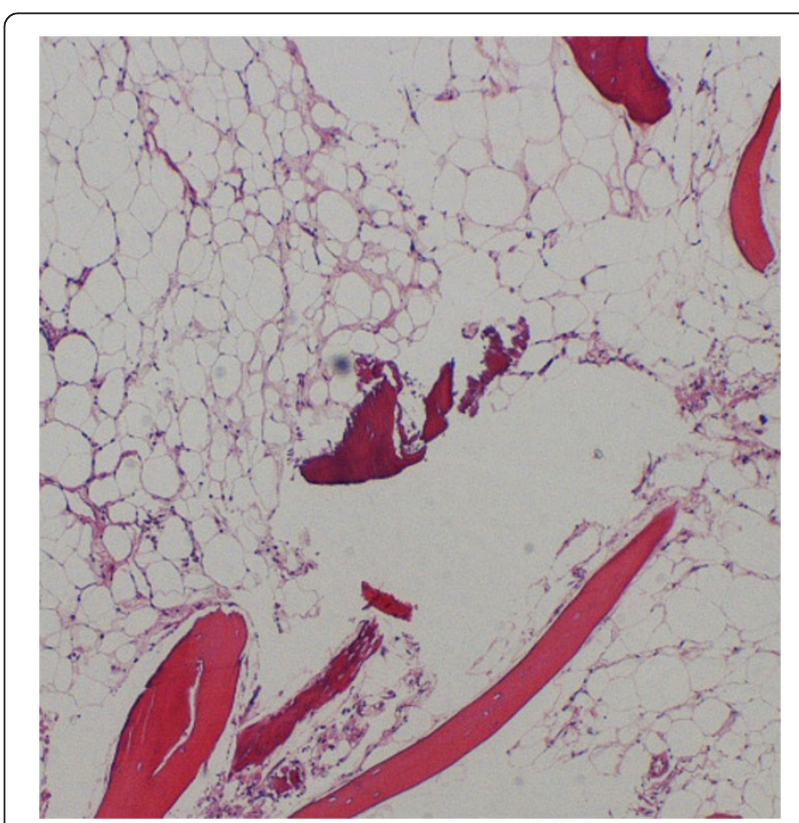

Figure 3 Intraoperative pathological findings of hyperplasia of adipose cells and blood vessels, a small amount of trabecular bone and adipose cells of different sizes. (Hematoxylin and eosin $\times 4$ magnification). 


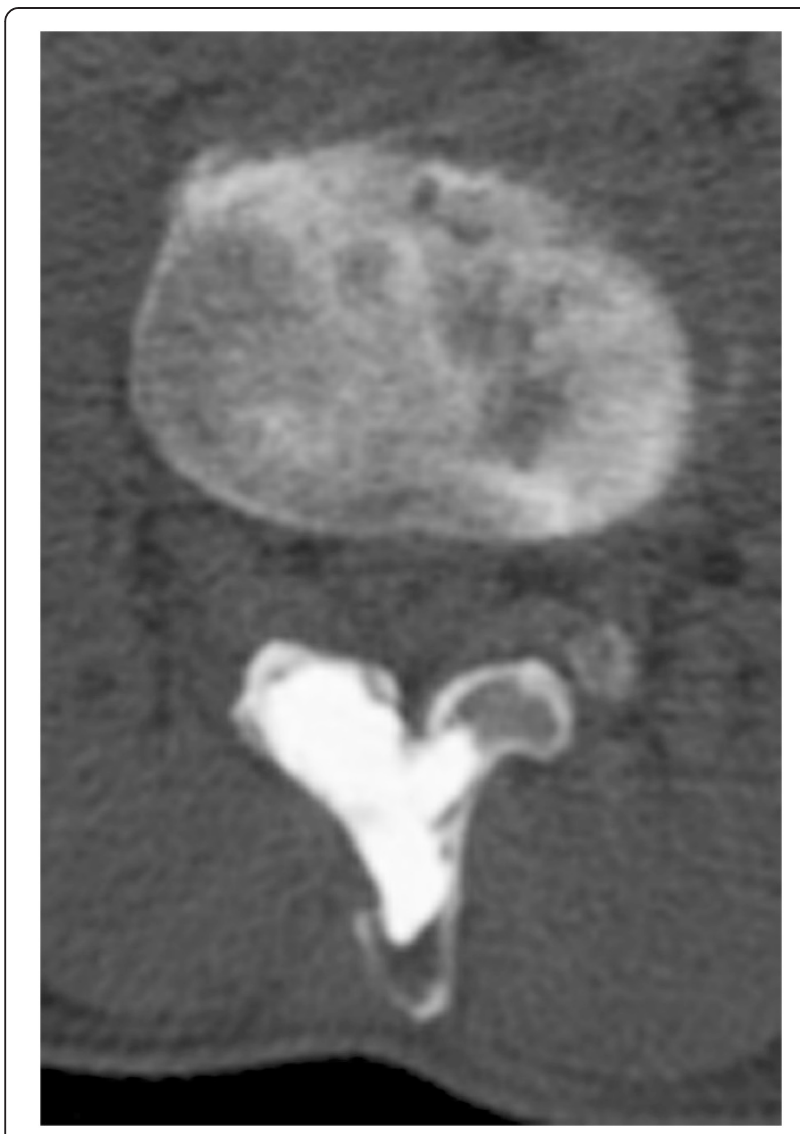

Figure 4 Computed tomography image three years after surgery. calcaneus [2] and metaphysis of long bones [3]. Campbell et al. [2] reported that lipomas occur most frequently in the calcaneus (32\%), while Milgram [3] found that lipomas occur most frequently in the metaphysis of the proximal femur (34\%).

We performed a review of the literature on intraosseous lipoma involving the spine, identifying only 14 cases (Table 1); five cases (35\%) occurred in the lumbar region, four $(28 \%)$ in the sacral region, three $(21 \%)$ in the cervical region, one $(7 \%)$ in the thoracic region and one (7\%) in the coccygeal region [4-14]. A slight predominance towards the lumbar spine was seen compared with other regions. The lesion in our patient also occurred in the lumbar region. Intraosseous lipoma in the lumbar region might occur at the vertebral body or in the posterior element $[8,12]$, with a slight predominance toward the vertebral body. However, our patient presented with the lesion in the posterior element.

Even though intraosseous lipoma is a benign tumor that can be successfully treated with conservative treatment, surgery has been recommended for diagnostic confirmation, painful tumors, pathological fractures and malignant transformation [1-3,15,16]. In our patient, low back pain persisted after conservative treatment, so we performed curettage and filled the defect with hydroxyapatite bone. Most cases of intraosseous lipoma have no pain, however, micro-movement of the periosteum of the L3 vertebral arch and spinous process may have caused our patient's pain. Subsequently, the low back pain of our patient was improved immediately after filling the curetted defect with hydroxyapatite, and no recurrence of tumor has been observed as of three years postoperatively.

Table 1 Spinal intraosseous lipoma reported in the literature

\begin{tabular}{|c|c|c|c|c|c|}
\hline Author & Published year & Patient's age & Gender & Site of involvement & Treatment \\
\hline Bin et al. [4] & 2010 & 27 & Male & C1-2 vertebral body & Curettage and reconstruction \\
\hline Lin et al. [5] & 2009 & 37 & Female & C3 spinous process & Surgery \\
\hline Chang and Park [6] & 2003 & 38 & Male & T1 lamina & Excision \\
\hline Kamekura et al. [7] & 2002 & 49 & Male & Sacrum & Excision \\
\hline Pande et al. [8] & 1998 & 35 & Male & L1-2 vertebral body & Biopsy \\
\hline Williams et al. [9] & 1993 & 45 & Male & L1 vertebral body and neural arch & Biopsy \\
\hline Williams et al. [9] & 1993 & 38 & Female & L4 vertebral body & Observation \\
\hline Williams et al. [9] & 1993 & 47 & Male & L4 vertebral body & Observation \\
\hline Milgram [10] & 1991 & 28 & Female & Sacrum & Biopsy \\
\hline Ehara et al. [11] & 1990 & 53 & Male & Sacrum & Biopsy \\
\hline Milgram [3] & 1988 & 20 & Male & C2 vertebral body & N/A \\
\hline Matsubayashi et al. [12] & 1980 & 27 & Male & L4 spinous process & Laminectomy \\
\hline Hanelin et al. [13] & 1975 & 33 & Male & Coccyx & Coccygectomy \\
\hline Zorn et al. [14] & 1971 & 21 & Male & Sacrum & Biopsy \\
\hline
\end{tabular}




\section{Conclusions}

Symptomatic intraosseous lipoma of spine is very rare, but the patient may be surgically well-treated by curettage and reconstruction of the benign tumor.

\section{Consent}

Written informed consent was obtained from the patient for publication of this case and accompanying images. A copy of the written consent is available for review by the Editor-in-Chief of this journal.

\section{Abbreviations}

CT: Computed tomography; HU: Hounsfield units; MRI: Magnetic resonance imaging.

\section{Competing interests}

No funds were received in support of this work. No benefits in any form have been or will be received from a commercial party related directly to the subject of this manuscript.

\section{Authors' contributions}

$\mathrm{CT}$ drafted the manuscript, performed the first selection of articles, and KT and EK assessed the quality of the papers. KK, KT and EK treated the patient surgically, and TS revised the manuscript critically for its content. YK helped to draft and correct the manuscript. All authors read and approved the final manuscript.

\section{Author details}

${ }^{1}$ Department of Spinal Surgery and Medical Engineering, Mie University Graduate School of Medicine, 2-174 Edobashi, Tsu city, Mie 514-8507, Japan. ${ }^{2}$ Department of Orthopedic Surgery, Thammasat University Hospital, 2 Prachan Road, Bangkok 10200, Thailand. 'Department of Orthopedic Surgery, Saiseikai Matsusaka General Hospital, 1-15-6 Asahi-cho, Matsusaka city Mie 515-8557, Japan

Received: 2 October 2014 Accepted: 14 January 2015

Published online: 06 March 2015

\section{References}

1. Unni KK. Lipoma and liposarcoma. Dahlin's bone tumors. General aspect and data on 10165 cases. Philadelphia, PA: Lippincott-Raven; 2010. p. 298-302.

2. Campbell RS, Grainger AJ, Mangham DC, Beggs I, Teh J, Davies AM. Intraosseous lipoma: report of 35 new cases and a review of literature. Skeletal Radiol. 1984;12:209-12.

3. Milgram JW. Intraosseous lipomas. A clinicopathologic study of 66 cases. Clin Orthop Relat Res. 1988;231:277-302.

4. Bin Z, Xiao-guang L, Zhong-jun L, Liao H, Liang J, Feng W. Intraosseous lipoma of adjacent upper cervical vertebral bodies with significant paravertebral expansion. Chin Med J. 2010;123(21):3160-2.

5. Lin N, Ye Z-m, Li W. Intraoseous lipoma of the pelvis and spine: two cases reports. Orthop Surg. 2009;1:326-9.

6. Chang H, Park J. Intraosseous lipoma of the first thoracic vertebra: a case report. Spine. 2003;28:250-1.

7. Kamekura S, Nakamura K, Oda H, Inokuchi K, lijima T, Ishida T. Involuted intraosseous lipoma of the sacrum showing high signal intensity on T1-weighted magnetic resonance imaging (MRI). J Orthop Sci. 2002;7:274-80.

8. Pande KC, Ceccherini AF, Webb JK, Preston BJ. Intraosseous lipomata of adjacent vertebral bodies. Eur Spine J. 1998;7:344-7.

9. Williams CE, Close PJ, Meaney J, Ritchie D, Cogley D, Carty AT. Intraosseous lipomas. Clin Radiol. 1993:47:348-50.

10. Milgram JW. Involuted intraosseous lipoma of sacrum. Spine. 1991;16:243-5.

11. Ehara S, Kattapuran SV, Rosenberg AE. Case report 619. Intraosseous lipoma of the sacrum. Skeletal Radiol. 1990;19:375-6.

12. Matsubayashi T, Nakajima M, Tsukada M. Case report 118. Skeletal Radiol. 1980;5:131-3.

13. Hanelin LG, Sclamberg EL, Bardsley JL. Intraosseous lipoma of the coccyx. Report of a case. Radiology. 1975;114:343-4.
14. Zorn DT, Cordray DR, Randels PH. Intraosseous lipoma of bone involving the sacrum. J Bone Joint Surg Am. 1971;53:1201-4.

15. Goto T, Kojima T, ljima T. Intraosseous lipoma: a clinical study of 12 patients. J Orthop Sci. 2002:7(2):274-80.

16. Latham PD, Athanasou NA. Intraosseous lipoma within the femoral head a case report. Clin Orthop Relat Res. 1991;265:228-32.

\section{Submit your next manuscript to BioMed Central and take full advantage of:}

- Convenient online submission

- Thorough peer review

- No space constraints or color figure charges

- Immediate publication on acceptance

- Inclusion in PubMed, CAS, Scopus and Google Scholar

- Research which is freely available for redistribution 